Research Article

\title{
Research and Application of an Innovative 110 Mining Method in Gob-Side Half Coal Rock Entry Retaining
}

\author{
Eryu Wang $\mathbb{D},,^{1,2}$ Xiangdong Chen $\mathbb{D}^{1},{ }^{1}$ and Xiaojie Yang $\mathbb{D i D}^{2}$ \\ ${ }^{1}$ School of Mining and Coal Engineering, Inner Mongolia University of Science and Technology, Baotou, \\ Inner Mongolia 014000, China \\ ${ }^{2}$ State Key Laboratory for Geomechanics and Deep Underground Engineering, China University of \\ Mining \& Technology (Beijing), Beijing 100083, China
}

Correspondence should be addressed to Eryu Wang; tbp150602042@student.cumtb.edu.cn and Xiangdong Chen; 2020022391@ stu.imust.edu.cn

Received 20 August 2021; Accepted 4 October 2021; Published 19 October 2021

Academic Editor: Fan Feng

Copyright (c) 2021 Eryu Wang et al. This is an open access article distributed under the Creative Commons Attribution License, which permits unrestricted use, distribution, and reproduction in any medium, provided the original work is properly cited.

In order to solve the problems of the high cost and time consumption of half coal rock entry driving, low coal recovery rate, and stress concentration on filling support body of retained entry along gob, the innovative 110 mining method based on pressure relief by roof cutting was adopted in 6302 thin coal seam working face of Baoshan Coal Mine. First the technical principle and key technology of this mining method was presented. Then, through theoretical analysis and calculation, engineering experience, and field test, the key parameters such as the length of constant resistance anchor cable, the cutting angle and height of presplitting blasting, the charge structure, and the blocking-gangue support structure were determined and conducted in the retained entry. The broken expanded coefficient varying law of caved gangue with time and space was obtained, which revealed roof movement characteristic. The displacement monitoring curve of the roof and floor indicated that the maximum subsidence of the roof was about $150 \mathrm{~mm}$ and the maximum amount of floor heaving was $100 \mathrm{~mm}$, which were quite small. The field monitoring data indicated that the entry retaining effect is good, which indicated that the innovative 110 mining method can be an effective way for reducing the high cost and time consumption of half coal rock entry driving, enhancing the coal recovery rate and preventing the dynamic mine pressure disasters.

\section{Introduction}

Academician He et al. put forward the theory of "short cantilever beam by cutting roof "in 2008 [1], and based on this theory, He et al. put forward the technology of pillarless mining with gob-side entry automatically retaining by roof cutting and pressure relief, that is, the 110 mining method. Many scholars have studied this technology. Guo et al. [2] have determined the charge quantity and charge structure of presplitting blasting in Yaoqiao Coal Mine in order to achieve a better presplitting blasting effect during gob-side entry retaining by roof cutting and pressure relief. Gao et al. [3] solved the problem that it was difficult to control the gangue rib caved along cutting structural plane in thick coal seam by establishing mechanical model, numerical simulation, and field test. Sun et al. [4] analysed the stress state of roof in 1610 working face of Nantun Coal Mine and obtained the key parameters needed for gob-side entry retaining by roof cutting and pressure relief in thin coal seam. Liu et al. [5] adopted the 110 mining method in Xiaohezui Coal Mine, which solved the problem of severe mine pressure behavior caused by high ground stress and retained coal pillar.

Longwall mining has always been the main coal production mode in China. When using this mining method, it is generally necessary to excavate two mining entries in advance and set up a coal pillar for each mining face, which is called 121 mining method. With the increase in the strike length of the working face, the investment cost and amount of entry driving will increase significantly, especially for the 
time-consuming driving of half coal rock entry, and the residual coal pillar will also cause a large amount of coal resources loss [6]. Due to the exhausted coal resources, it is particularly important to improve the coal recovery rate, so the nonpillar mining technology of gob-side entry retaining was more and more applied to the coal mining project. However, at present, the gob-side filling support body was mainly used to retain the entry along the gob [7]. This method does not change the mechanical structure of the entry surrounding rock. Because the filling body is the main pressure-bearing structure, it is easy to lead to the problem of dynamic disaster caused by stress concentration [8]. Also, dynamic mine pressure causes serious entry deformation, resulting in the high cost of entry maintenance and affecting the safety of mine production [9].

In order to overcome above problems, taking the longwall panel 6302 of Baoshan Coal Mine as the research background, this study did research on the application of the innovative 110 mining method in gob-side half coal rock entry retaining. Through pressure relief by roof cutting, the roof structure and stress distribution of the surrounding rock of the entry were improved, and the entry side filling support body was replaced by the broken expanded caving gangue, which avoids the stress concentration on the filling body caused by dynamic roof pressure; the high cost and time consumption of half coal rock entry driving were reduced significantly, and the nonpillar mining was realized completely. The technical principle and key technologies of 110 mining method were introduced first in the study. Then, the parameters of key technologies were determined and conducted in the retained entry. The roof movement characteristic was revealed through the obtained broken expanded coefficient varying law of caved gangue with time and space. The field monitoring data indicated that the entry retaining effect is good. These results provide a reliable mining method for the reduction of the high cost and time consumption on half coal rock entry driving, enhancing the coal recovery rate, preventing the dynamic mine pressure disasters, and effectively guaranteeing the safe, economic, and efficient mining of coal mines in China.

\section{General Situation of the Project}

The buried depth of coal seam in 6302 working face of Baoshan Coal Mine is $53.5-73.7 \mathrm{~m}$, the average buried depth is $63.6 \mathrm{~m}$, and the dip angle of coal seam is $1-3^{\circ}$; it is a near-horizontal coal seam, and the thickness of coal seam is $1.5-1.6 \mathrm{~m}$, with an average of $1.55 \mathrm{~m}$. The comprehensive geological histogram of the working face is shown in Figure 1. Both the belt entry and ventilation entry of 6302 working face were half coal rock entry with width of $5 \mathrm{~m}$ and height of $2.45 \mathrm{~m}$, as shown in Figure 1 . The driving of the half coal rock entry cost high and consume much time. The length of the working face is $200 \mathrm{~m}$, the longwall comprehensive mechanized mining method is adopted, and the roof is managed by all caving method. The longwall panel 6302 working face adopts the automatic entry forming technology of 110 mining method, the designed retaining entry is 6302 belt entry, as shown in Figure 2, and the length of the designed retained entry is $890 \mathrm{~m}$. The retained coal pillar with a width of $15 \mathrm{~m}$ was cancelled. Excavation rate half coal rock entry was reduced by $50 \%$.

\section{Key Techniques}

The technological process of 110 mining method is as follows: before the mining of the working face, the roof of the retaining entry was supported by constant resistance and large deformation anchor cable(CRLD anchor cable); then, along the entry strike, the directional presplitting cumulative blasting was carried out on the roof side of the working face; then, the roadside support was carried out after the working face was supported; after the working face was mined for a certain distance, the roof collapsed along the presplitting face and the caved gangue filled the gob due to the broken expanding effect, and then, the entry was retained. The schematic diagram is shown in Figure 3.

3.1. CRLD Anchor Cable Support Technology. In order to resist the large deformation of entry surrounding rock, He et al. developed constant resistance large deformation anchor cable $[10,11]$. The constant resistance large deformation anchor cable was composed of an anchor cable body, a constant resistor, an anchor cable tray, and a lock. The specific structure is shown in Figure 4.

The constant resistor was the key component of the CRLD anchor cable. When the axial force of the constant resistance anchor cable was greater than the constant resistance value, the constant resistance body and casing occurred slip deformation to absorb the deformation energy of the entries surrounding rock, making the entry surrounding rock in stress balance again [12]. The arrangement of CRLD anchor cable in the entry roof was on the side of the gob, which can prevent the roof sinking and separation, resist the impact caused by the fracture of the main roof, greatly weaken the rotation movement of the basic roof, and resist the blasting impact disturbance of presplitting blasting on the entry roof of gob side.

CRLD anchor cable plays an important role in the stability control of the roof cutting process. According to the engineering experience of CRLD anchor cable length design, the length of CRLD anchor cable is generally 1.5 2 m larger than the cutting height of presplitting blasting, and the cutting height is designed to be $5 \mathrm{~m}$. Combined with the lithology distribution of roof strata, the length of constant resistance anchor cable was designed to be $7.3 \mathrm{~m}$.

Two rows of CRLD anchor cable were arranged perpendicular to the entry roof of longwall panel 6302, the first row of CRLD anchor cable was arranged at the distance from the entry side $500 \mathrm{~mm}$, the row distance was $1000 \mathrm{~mm}$, and the CRLD anchor cable was connected with W steel belt; the second row of constant resistance anchor cables was arranged in the middle of the entry, and the row distance was $3000 \mathrm{~mm}$. The support plan of CRLD anchor cable in longwall panel 6302 of Baoshan Coal Mine is shown in Figure 5. 


\begin{tabular}{|c|c|c|c|}
\hline Columnar & Rock stratum & Thickness (m) & Lithology description \\
\hline 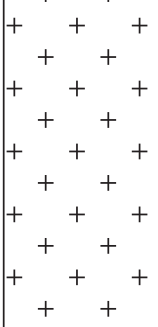 & Fine sandstone & 13.92 & $\begin{array}{l}\text { Grayish white, thick layer, mainly } \\
\text { composed of quartz and feldspar, } \\
\text { argillaceous cementation, semi-hard }\end{array}$ \\
\hline 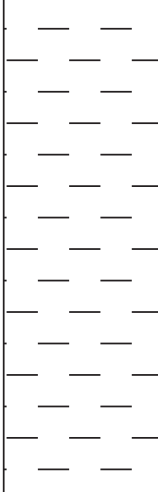 & Sandy mudstone & 23.2 & $\begin{array}{l}\text { Dark grey, edge angle, horizontal } \\
\text { texture,containing incomplete plant } \\
\text { fossils, semi-hard }\end{array}$ \\
\hline 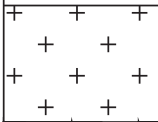 & Fine sandstone & 3.78 & $\begin{array}{l}\text { Grayish white, thick layer, mainly } \\
\text { composed of quartz and feldspar, } \\
\text { semi-hard, hype-edge angle }\end{array}$ \\
\hline घ: & Coal seam & 1.60 & $\begin{array}{l}\text { Black, dim type, stratified } \\
\text { structure,banded structure }\end{array}$ \\
\hline$-1-2$ & Sandy mudstone & 3.00 & $\begin{array}{l}\text { Dark grey,thin bedded, horizontal texture, } \\
\text { containing incomplete plant fossils }\end{array}$ \\
\hline
\end{tabular}

FIGURE 1: Comprehensive geological histogram of working face.

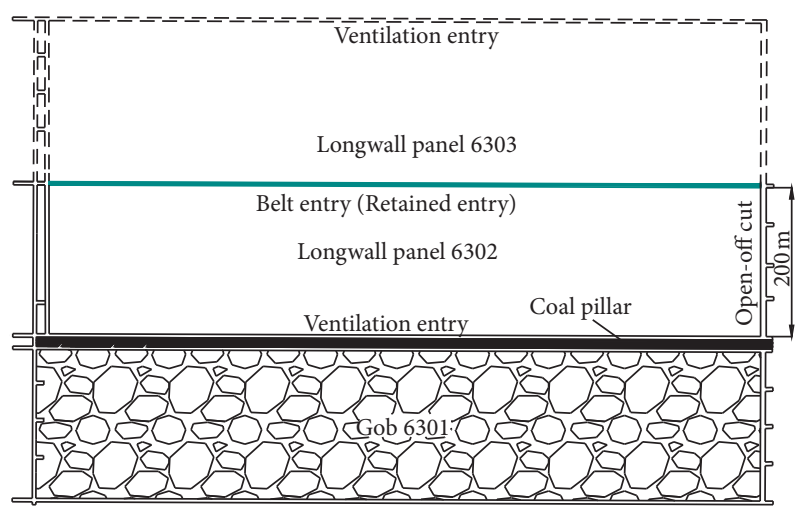

Figure 2: Plane layout of the mining panel.

\subsection{Directional Splitting Blasting Technology.} Bidirectional energy cumulative tension blasting technology is a new type of rock mass energy cumulative controlled blasting patent technology invented by Academician $\mathrm{He}$ et al. [13]. The bidirectional energy cumulative tube was utilized to produce tensile stress concentration in the set direction [14], due to the high compressive strength and low tensile strength properties of the rock $[15,16]$. It refers to put the explosive into the bidirectional energy cumulative tube.

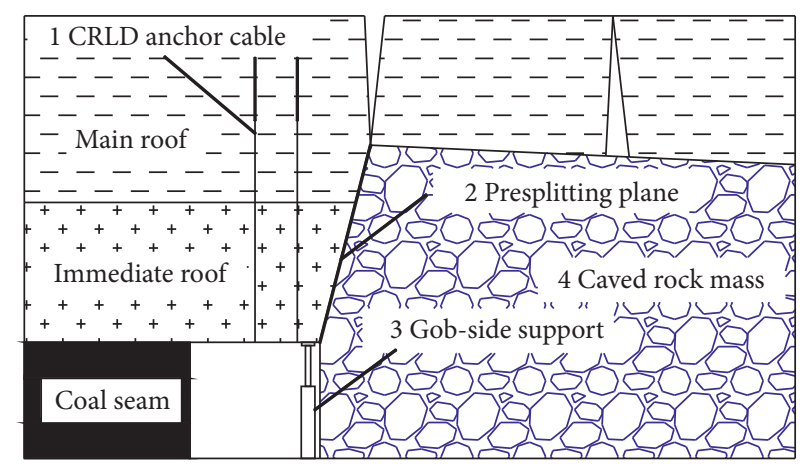

FIGURE 3: The schematic diagram of cutting roof retaining entry.

After the explosive is detonated, the surrounding rock of the blast hole is intensively tensioned in the set direction, so as to realize the tension fracture forming according to the set direction. Its principle is illustrated in Figure 6.

\subsubsection{Roof Cutting Height of Presplitting Blasting.} Directional presplitting tension blasting is the key process of pressure relief by roof cutting. Only when the appropriate cutting height is determined, can the caved gangue, which is 


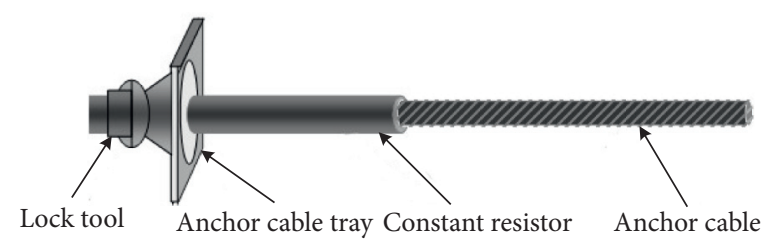

FIgURE 4: Structure diagram of CRLD anchor cable.

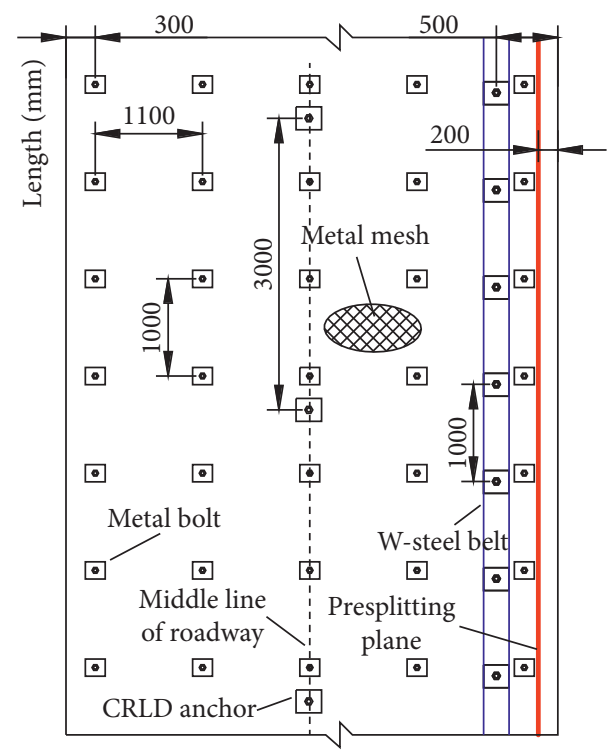

Figure 5: Section view of CRLD anchor cable support.

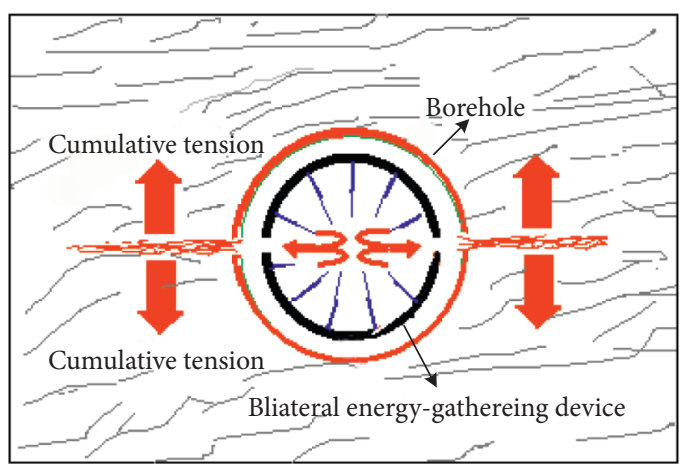

Figure 6: Schematic diagram of bidirectional energy cumulative tension blasting.

cutoff, fill the gob and have sufficient support force for the movement of the basic roof beam above it. The cutting height is generally determined by the following ways:

$$
H_{f}=\frac{\left(H_{c}-\Delta H_{1}-\Delta H_{2}\right)}{(K-1)},
$$

where $H_{c}$ is the mining height of working face; $\Delta H_{1}$ is roof subsidence, $m ; \Delta H_{2}$ is bottom heave, $m$; and $K$ is swelling expanded coefficient, 1.3-1.5.

For the longwall panel 6302, $K$ is 1.35 , mining height is $1.6 \mathrm{~m}$, without considering roof and floor displacement, $H_{f}=4.57 \mathrm{~m}$ is calculated. According to engineering experience and comprehensive geological histogram, the cutting height was designed to $5 \mathrm{~m}$.

3.2.2. Roof Cutting Angle of Presplitting Blasting. When the basic roof strata is within the range of the cutting height, the choice of the cutting angle directly affects whether the roof can collapse smoothly and the gob is filled adequately. According to a great deal of engineering experience, the roof cutting angle $\theta$ was determined by different mining height $H_{c}: H_{c} \leq 1 \mathrm{~m}, \theta=20^{\circ} ; 1 \mathrm{~m}<H_{c} \leq 3 \mathrm{~m}, \theta=15^{\circ} ; 3 \mathrm{~m}<H_{c} \leq 5 \mathrm{~m}$, $\theta=10^{\circ}$. The mining height of longwall panel 6302 was $1.6 \mathrm{~m}$, so the roof cutting angle was designed to be $15^{\circ}$.

3.2.3. Blasting Process Parameters. First of all, the blast hole is drilled in the roof, and then, the single-hole blasting is carried out. Whether the crack initiation in the hole meets the requirements is peeped and observed, so as to determine the best structure of the single-hole charge, and then, the adjacent hole test is carried out to determine the optimal distance between the two adjacent holes and finally carry out a single detonation number test to determine the best number of detonation blasting holes at one time.

Bidirectional decoupling charge in radial and axial direction was adopted in directional presplitting blasting. According to the field test results, the optimal charge structure is shown in Figure 7; the optimum charge quantity of single hole in presplitting blasting was " $3+2$," the distance between blasting holes was $500 \mathrm{~mm}$, there were 2 energy cumulative tubes per hole, the optimum mud sealing length was $2 \mathrm{~m}$, and the specification of explosive was $\varphi 32 \times 200 \mathrm{~mm}$ with a quality of $300 \mathrm{~g}$.

3.2.4. Blasting Effect. After blasting, CXK6 mine borehole imager was used to detect internal cracks of the blasting hole, and the images were transformed into a plan, as shown in Figure 8. From the observation results, it can be seen that the penetrating crack rate of the blasting hole was $89 \%$, two penetrating cracks formed along the designed presplitting cutting angle and cutting height, which indicated a perfect blasting effect.

\subsection{Blocking-Gangue Support System}

3.3.1. Gangue Support. In the process of fully mechanized mining face advancing, in order to obtain good entry side forming effect and gangue broken expanding effect, entry side gangue support need to be carried out. According to the engineering characteristics of gob-side entry automatically retaining by roof cutting and pressure relief, we put forward the "retractable U-shaped steel + Rigid hydraulic prop + Metal mesh" entry side gangue support technology, which can resist and release the dynamic pressure caused by the fracture of cutting roof and main roof and greatly weaken the rotation movement of entry roof.

As shown in Figure 9, the blocking-gangue support was installed alternately with $\mathrm{U}$-shaped steel and hydraulic prop, and the distance between adjacent U-shaped steel and 


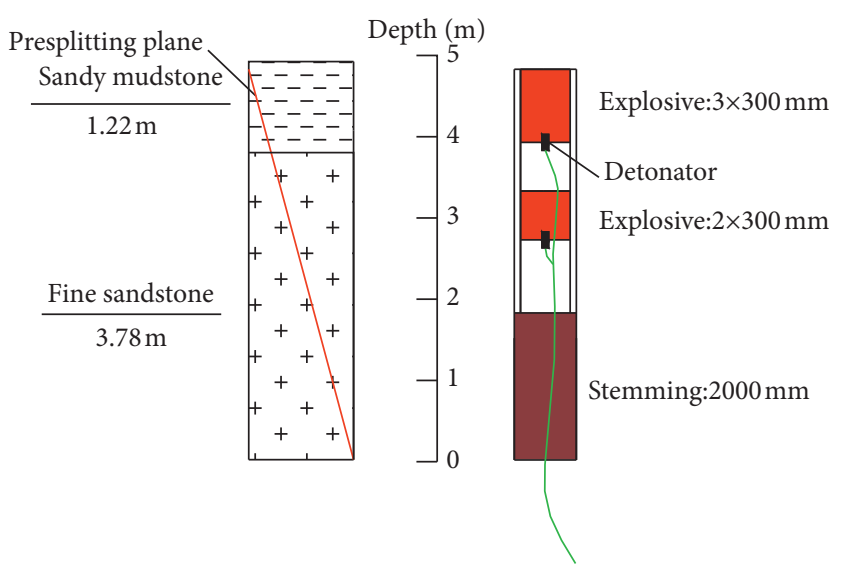

FIgURE 7: Diagram of blast hole charge structure.

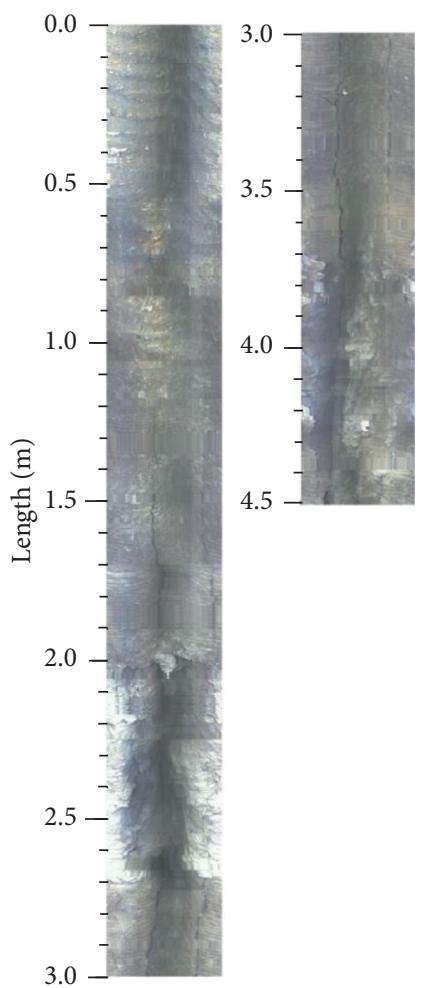

FIgURE 8: Blasting effect plan.

hydraulic prop was $250 \mathrm{~mm}$; the hydraulic prop and U-shaped steel were located in the cutting position, the retractable $25 \mathrm{U}$-shaped steel was lapped up and down, the length of U-shaped steel was $1.5 \mathrm{~m}$, and the depth of $\mathrm{U}$-shaped steel buried below the floor should be larger than $300 \mathrm{~mm}$.

3.3.2. Effect of Blocking-Gangue Support. After the gangue caved by cutting roof was constantly compacted due to the subsidence of the main roof and enter into a stable state, the working resistance change of the hydraulic prop was very small. At this time, the single hydraulic prop for temporary support can be removed, leaving only retractable U-shaped

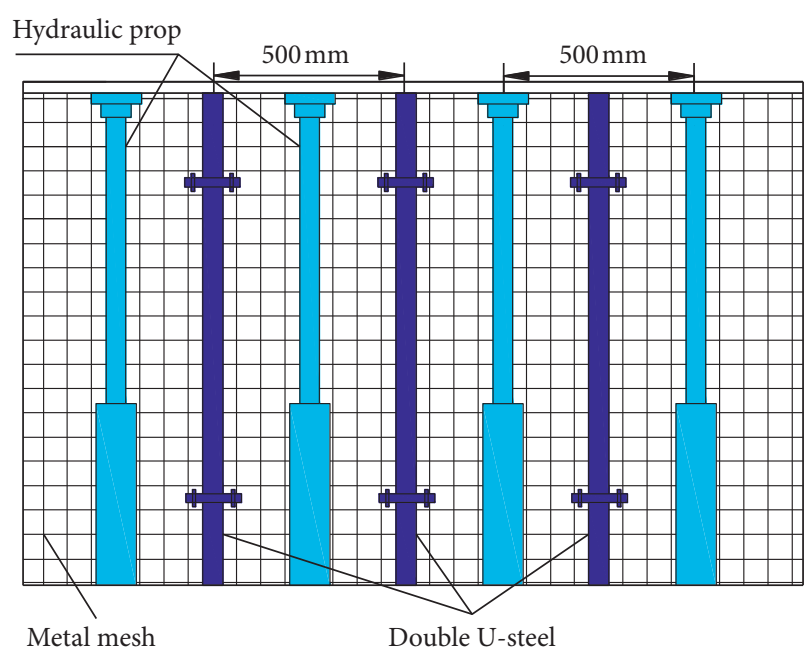

FIGURE 9: Side view of blocking-gangue support.

steel and metal mesh for gangue support. The effect of blocking gangue is shown in Figure 10.

\section{Broken Expanding Law of Cutting Roof}

Making use of broken expansion property of rock to make the collapsed roof to fill the gob is the key to the stability of automatically retaining entry. The hydraulic props connected with the lace beam were set to reduce the entry roof subsidence caused by cutting roof collapse, reduce main roof fracture and rotation [17], and promote the broken expansion effect, as shown in Figure 11. The hydraulic props could be removed after the entry subsidence was stable. Through the combination of the broken expansion of the roof, the inside hydraulic props support, and the blockinggangue support, the gob can be better filled, the impact of the cutting roof collapse and main roof fracture was weakened, the periodic pressure step distance was increased, the periodic compression strength of the main roof was also greatly reduced, and the automatically retaining entry was more stable.

The measuring points were arranged continuously during the advancing process of longwall panel 6302 in Baoshan Coal Mine, and the rock swelling coefficient of the measuring point was measured. Through the field measurement of the longwall panel 6302, the variation curve of the rock broken expansion coefficient of the measuring point with the advancing distance and advancing time of the working face was obtained, as shown in Figure 12.

Through the variation curve of the broken expansion coefficient of each measuring point with the advancing distance and time of the working face, it was known that with the increase in time and the advancing distance of the working face, the broken expansion coefficient of rock decreases rapidly, especially during the period of periodic pressure, and then, the broken expansion coefficient tends to be stable gradually. The broken expansion coefficient decreased gradually from about $1.84 \sim 1.88$ at the beginning and finally stabilized between 1.3 and 1.38 . Within 12 days of roof collapse and within $60 \mathrm{~m}$ of lagging face distance, the 


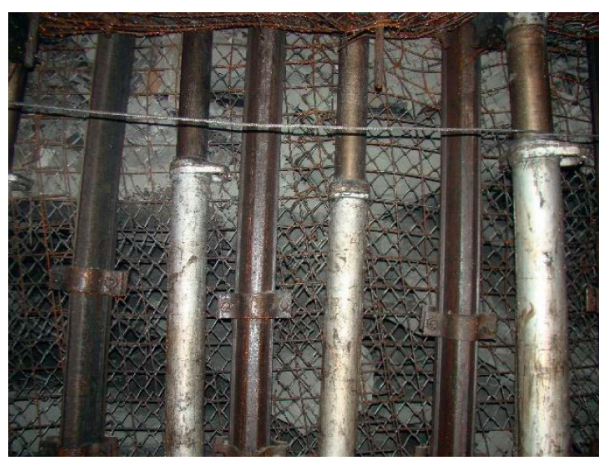

(a)

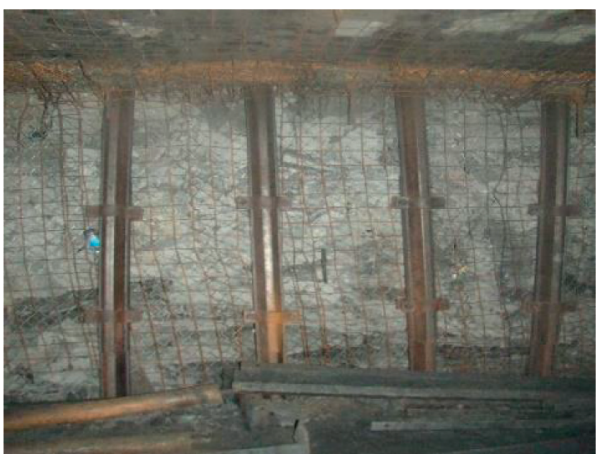

(b)

FIGURE 10: Effect of blocking gangue. (a) Blocking-gangue support installation. (b) Hydraulic prop remove.

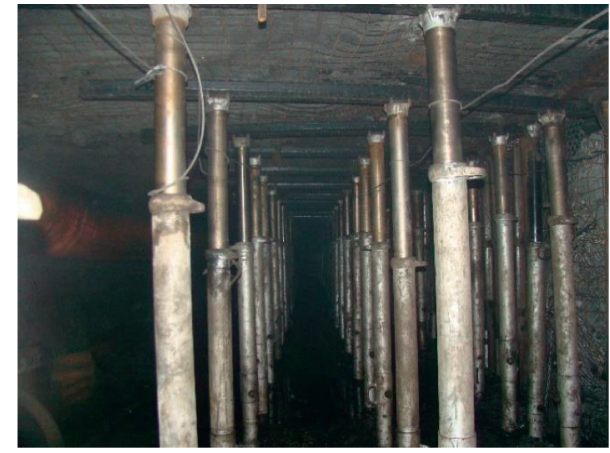

Figure 11: Effect of blocking gangue.

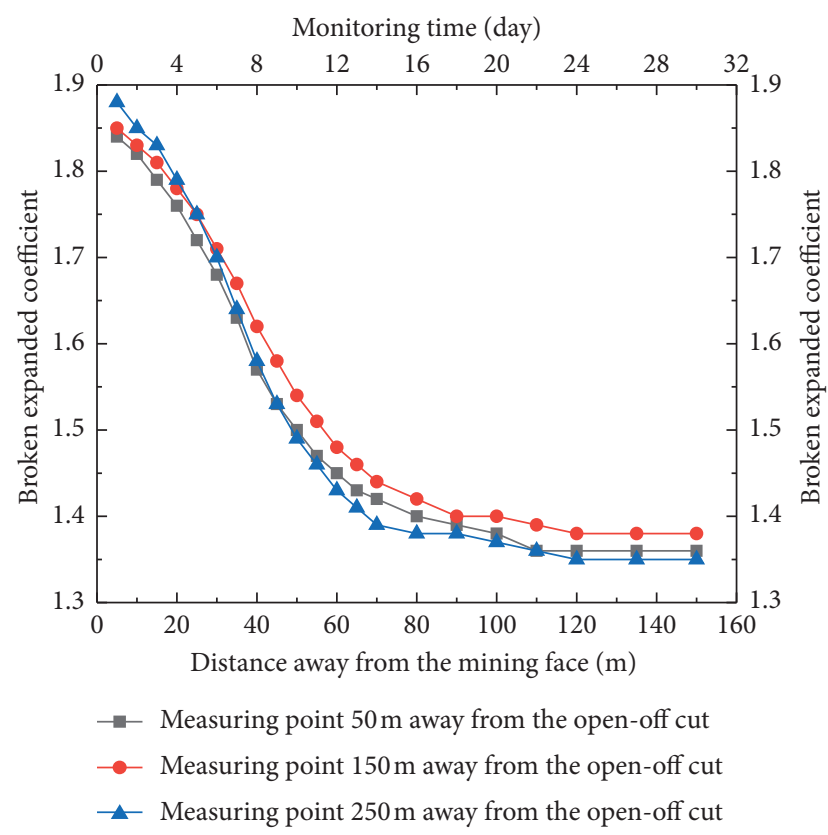

FIGURE 12: Curve of broken expansion coefficient change with monitoring time and advancing distance of working face.

decreasing rate of broken expansion coefficient was the largest, especially within $25 \mathrm{~m} \sim 50 \mathrm{~m}$, indicating that the roof movement was the most intense in this range, and the periodic pressure caused by main roof fracture and rotation has a significant effect on the compaction of gangue. From 12 days to 24 days, the distance of lagging face was about $60 \mathrm{~m} \sim 120 \mathrm{~m}$, and the expansion coefficient tended to be stable gradually. After 24 days, when the distance of the lagging face was $120 \mathrm{~m}$, the broken expansion coefficient was basically stable, indicating that the cutting roof was compacted, and the basic roof and the overlying strata were in a stable state.

\section{Engineering Application Effect}

During the period of entry retaining in the longwall panel 6302 of Baoshan Coal Mine, the monitor of the displacement of roof and floor can reflect the stress and deformation of the entry surrounding rock, so the displacement of the roof and floor was measured in the field.

5.1. Monitoring of Displacement of Entry Roof and Floor. The displacement curve of the roof and floor can be obtained from the field monitoring data, as shown in Figure 13. It can be seen from the figure that with the advance of the working face, the roof and floor gradually deform. In lagging working face of $0-60 \mathrm{~m}$, the displacement rate of roof and floor were the largest due to dynamic pressure behavior caused by cutting roof caving and fracture of main roof, the displacement of roof and floor was about $190 \mathrm{~mm}$, and the increment of roof subsidence was about $120 \mathrm{~mm}$. In lagging working face of $60-120 \mathrm{~m}$, the increment of roof and floor subsidence was about $40 \mathrm{~mm}$, the displacement increment of roof was about $20 \mathrm{~mm}$, the displacement rate of roof and floor reduced significantly due to the support of compacted broken expanded gangue to the fractured main roof. In lagging working face of $120 \sim 200 \mathrm{~m}$, the increment of roof and floor subsidence was about $20 \mathrm{~mm}$, the increment of roof subsidence was about $10 \mathrm{~mm}$, and then, the displacement curve of the roof and floor tends to be smooth gradually. When the deformation of roof and floor was stable, the maximum displacement of roof and floor was about $250 \mathrm{~mm}$, the maximum subsidence of the roof was about $150 \mathrm{~mm}$, and the maximum amount of floor heaving was $100 \mathrm{~mm}$, which were in the small deformation range. The monitoring results show that the effect of retaining entry is good. 


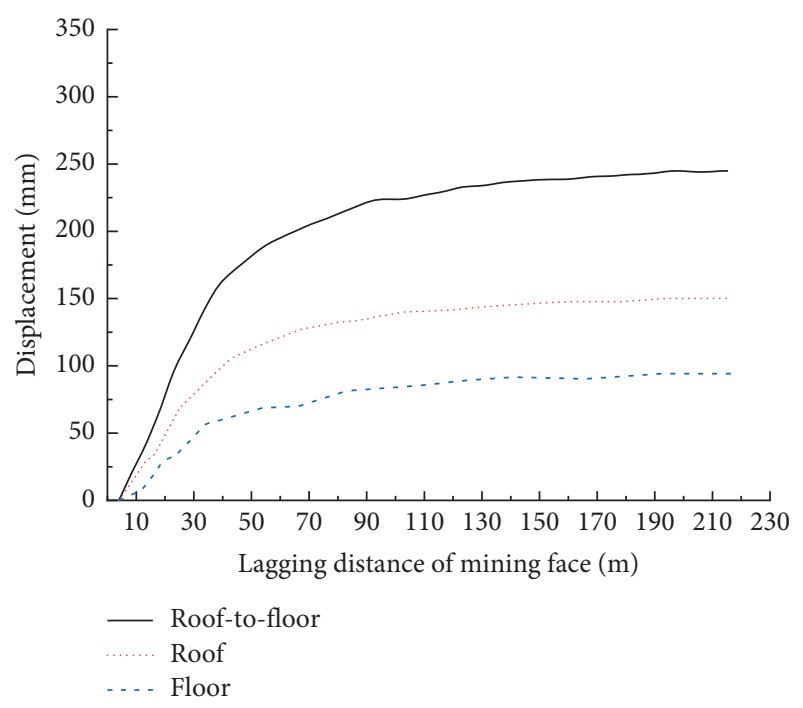

Figure 13: Displacement curve of top and bottom plate.

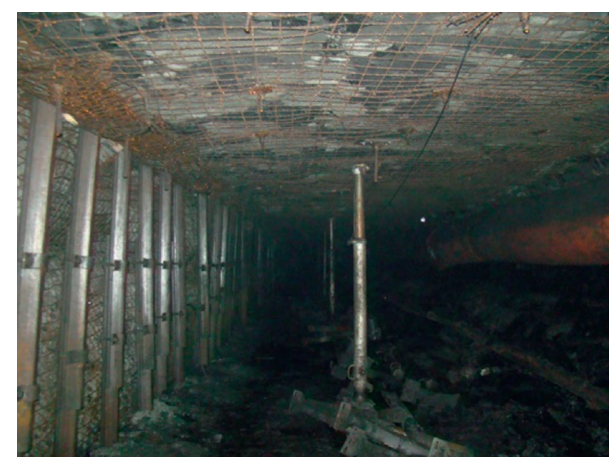

Figure 14: Effect of on-site entry retaining.

5.2. On-Site Entry Retaining Effect. Pillarless mining with gob-side entry automatically retaining by roof cutting and pressure relief was carried out in the main transport trough of longwall panel 6302 in Baoshan Coal Mine. The bidirection energy cumulative blasting technology was used to presplit the roof near the working face, along with the mining of the working face, under the action of CRLD anchor cable and blocking-gangue support, the roof automatically collapsed along the presplitting cutting plane to form a gangue rib and support the main roof due to the broken expanding effect; the stress transfer between the entry roof and gob roof was also cutoff, and these greatly reduced the pressure from the gob. In the process of roof cutting and retaining entry, the damage degree of surrounding rock of entry was small, the whole was relatively intact, and the effect of entry retaining was good, which meet the requirements of entry reuse in the longwall panel 6303. The effect of retaining entry is shown in Figure 14.

\section{Conclusion}

(1) Under the condition of thin coal seam in Baoshan Coal Mine, the 110 mining method was adopted in longwall panel 6302, which mainly included CRLD anchor cable support technology, directional presplitting blasting technology, and blocking-gangue support technology; the technical parameters of these key technologies were made through theoretical analysis, engineering experience, and field test.

(2) Through the variation curve of the swelling coefficient with time and the advancing distance of the working face, the swelling law of the caved gangue duo to roof cutting and the movement law of the main roof were revealed.

(3) According to the field monitoring data, the entry deformation was small, and the entry retaining effect was good; the stress transfer between the entry roof and gob roof was cutoff, the periodic pressure of the main roof fracture and rotation was significantly weakened, the periodic pressure step distance was increased, and the periodic pressure strength of the main roof was also greatly reduced.

(4) The 110 mining method bring significant technical and social and economic benefits. The technology of pillarless mining with gob-side entry automatically retaining by roof cutting and pressure relief greatly improved the recovery rate of Baoshan coal mine. Due to the reuse of retaining entry, high cost and time consumption of half coal rock entry driving of entry driving was also greatly reduced, and the problem of tense mining replacement situation of mining was also solved. These provided valuable application results of economic, safe, and efficient recovery technology for coal resources mining in the future.

\section{Data Availability}

All data included in this study are available upon request by contact with the corresponding author.

\section{Conflicts of Interest}

The authors declare no conflicts of interest.

\section{Authors' Contributions}

Eryu Wang and Xiaojie Yang conceived the theme; Eryu Wang performed the field tests; Xiaojie Yang provided theoretical and technical guidance; Xiangdong Chen processed and analyzed the data. Eryu Wang and Xiangdong Chen wrote the paper. All authors have read and agreed to the published version of the manuscript.

\section{Acknowledgments}

This work was supported by the National Natural Science Foundation of China (no. 52064042), the Inner Mongolia Natural Science Foundation (Grant no. 2020BS05004), and the Innovation Fund Project of Inner Mongolia University of Science and Technology (Grant no. 2019QDL-B34), which are gratefully acknowledged. 


\section{References}

[1] M. He, G. Zhu, and Z. Guo, "Longwall mining "cutting cantilever beam theory" and 110 mining method in China-- the third mining science innovation," Journal of Rock Mechanics and Geotechnical Engineering, vol. 7, no. 5, pp. 483-492, 2015.

[2] P. Guo, G. Zhan, and Z. Tao, "Blasting technology of gateway retaining along gob pressure release by roof cutting in hard and weak complex roof," Coal Science and Technology, vol. 44, no. 10, pp. 120-124, 2016.

[3] Y. Gao, J. Yang, M. He, Y. Wang, and Q. Gao, "Mechanism and control techniques for gangue rib deformations in gobside entry retaining formed by roof fracturing in thick coal seams," Chinese Journal of Rock Mechanics and Engineering, vol. 36, no. 10, pp. 2492-2502, 2017.

[4] X. Sun, X. Liu, G. Liang, D. Wang, and Y. Jiang, "Key parameters of gob-side entry retaining formed by roof cut and pressure releasing in thin coal seams," Chinese Journal of Rock Mechanics and Engineering, vol. 33, no. 7, pp. 1449-1456, 2014.

[5] X. Liu and G. Zhang, "Technology of roof cutting pressure relief gob-side entry retaining in soft fractured stratum," Coal Science and Technology, vol. 41, no. S2, pp. 133-134, 2013.

[6] Qi Wang, M. He, J. Zhenhua, Y. Wang, Q. Qin, and B. Jiang, "Comparative study of model tests on automatically formed entry and gob-side entry driving in deep coal mines," International Journal of Mining Science and Technology, vol. 31, no. 4, pp. 591-601, 2021.

[7] Q. Chang, W. Tang, Y. Xu, and H. Zhou, "Research on the width of filling body in gob-side entry retaining with highwater materials," International Journal of Mining Science and Technology, vol. 28, no. 3, pp. 519-524, 2018.

[8] M. He, S. Chen, Z. Guo, J. Yang, and Y. B. Gao, "Control of surrounding rock structure for gob-side entry retaining by cutting roof to release pressure and its engineering application," Journal of China University of Mining and Technology, vol. 46, no. 5, pp. 959-969, 2017.

[9] X. Hua, "Development status and improved proposals on gobside entry retaining support technology in China," Coal Science and Technology, vol. 34, no. 12, pp. 78-81, 2006.

[10] M. He, C. Li, W. Gong, and Li Shenglin, "Dynamic tests for a Constant-Resistance-Large-Deformation bolt using a modified SHTB system," Tunnelling and Underground Space Technology incorporating Trenchless Technology Research, vol. 64, 2017.

[11] C. Zhu, M. C. He, X. H. Zhang, Z. G. Tao, Q. Yin, and L. F. Li, "Nonlinear mechanical model of constant resistance and large deformation bolt and influence parameters analysis of constant resistance behavior," Rock and Soil Mechanics, vol. 42, no. 7, pp. 1911-1924, 2021.

[12] M. He, W. Gong, J. Wang et al., "Development of a novel energy absorbing bolt with extraordinarily large elongation and constant resistance," International Journal of Rock Mechanics and Mining Sciences, vol. 67, pp. 29-42, 2014.

[13] M. He, X. Zhang, and S. Zhao, "Directional destress with tension blasting in coal mines," Procedia Engineering, vol. 191, 2017.

[14] M. He, W. Cao, R. Shan, and S. Wang, "New blasting technology-bilateral cumulative tensile explosion," Chinese Journal of Rock Mechanics and Engineering, vol. 22, no. 12, pp. 2047-2051, 2003.

[15] F. Fan, X. Li, J. Rostami, D. Peng, D. Li, and K. Du, "Numerical investigation of hard rock strength and fracturing under polyaxial compression based on Mogi-Coulomb failure criterion," International Journal of Geomechanics, vol. 19, no. 4, 2019.

[16] F. Fan, S. Chen, Y. Wang, W. Huang, and Z. Han, "Cracking mechanism and strength criteria evaluation of granite affected by intermediate principal stresses subjected to unloading stress state," International Journal of Rock Mechanics and Mining Sciences, vol. 143, no. 5, Article ID 104783, 2021.

[17] X. Yang, E. Wang, X. Ma, G. Zhang, R. Huang, and H. Lou, "A case study on optimization and control techniques for entry stability in non-pillar longwall mining," Energies, vol. 12, p. 391, 2019. 